\title{
Soroepidemiologia da infecção pelo vírus da leucose enzoótica bovina em rebanhos leiteiros da região do Caparaó/ES
}

Lukas Souza Felisberto, Ítalo Câmara de Almeida, Daniel Pacheco Ipólito, Raul Vargas Boechat, Graziela Barioni", Dirlei Molinari Donatele, Leonardo Camilato Lima Costa, Aline Nunes Simões, Áquila Flávia da Rocha Braga, Renan de Mello Spadeto

Centro de Ciências Agrárias e Engenharias, Universidade Federal do Espírito Santo (UFES), Vitória, ES, Brasil

*Autor correspondente

e-mail: grazibari@gmail.com

\section{Resumo}

A leucose enzoótica bovina (LEB) é uma doença infectocontagiosa causada por um retrovírus da família Retroviridae, subfamília Oncovirinae e gênero Deltaretrovirus, denominado vírus da leucose bovina, com registros por todo o mundo e se alastrando progressivamente pelos rebanhos, o que determina grandes prejuízos à bovinocultura brasileira, principalmente no rebanho leiteiro. Fato que se agrava devido ao aumento da densidade de animais importados e uso de manejos inadequados, que contribuem para maior disseminação nacional da LEB. 0 objetivo do presente trabalho foi determinar a soroprevalência da infecção pelo vírus da LEB e os principais fatores de risco da infecção no rebanho bovino leiteiro de municípios da região do Caparaó, Espírito Santo. Foram visitadas 70 propriedades de bovinocultura leiteira, de escolha aleatória nos 12 municípios da região, na qual amostras sanguíneas foram coletadas de todos os animais em lactação, por meio de punção da veia coccígea em sistema de coleta a vácuo, totalizando 914 amostras. Os tubos foram identificados, armazenados em caixas isotérmicas com gelo reciclável e encaminhados para processamento no Hospital Veterinário (HOVET/CCAE-UFES). Os soros foram examinados pelo Teste de Imunodifusão em Ágar Gel (IDGA) para a detecção dos anticorpos específicos contra o vírus da leucose bovina (VLB). As associações entre as variáveis foram testadas pelo teste Qui-quadrado $\left(\mathrm{X}^{2}\right)$, com nível de significância de 5\%. Os municípios da região do Caparaó estão em sua totalidade infectados com o vírus da LEB, apresentando 55,90\% de prevalência. Das propriedades analisadas, 94,28\% apresentam animais infectados em seu rebanho. 0 uso de ocitocina no momento da ordenha e o uso de ordenhadeira mecânica foram fatores de risco para a LEB na região, apresentado OddsRatio (OR) de 1,945 e 1,858, respectivamente. Conclui-se que a leucose enzoótica bovina está amplamente difundida nos rebanhos leiteiros da região do Caparaó, sul do Espírito Santo, devendo haver maiores estudos para todo o estado, assim como aplicar medidas de controle e prevenção na região.

Apoio Financeiro: Fundação de Amparo à Pesquisa e Inovação do Espírito Santo (FAPES). 